Samuel Schmidt; Carlos Spector,

Cuadernos de $\mathrm{H}$ Ideas, vol. 11, $\mathrm{n}^{\circ}$. 11, e002, diciembre 2017

ISSN 2313-9048 | https://doi.org/10.24215/23139048e002

http://perio.un/p.edu.ar/ojs/index.php/cps/index

FPyCS | Universidad Nacional de La Plata

La Plata | Buenos Aires | Argentina

\title{
Crimen autorizado. Una revisión
}

\section{Authorized Crime. A review}

\section{Samuel Schmidt}

Universidad de Texas, Austin. Contacto: shmil50@hotmail.com

\section{Carlos Spector}

Contacto: spectorimm@yahoo.com

\section{Resumen}

El Crimen Autorizado es una forma de asociación entre segmentos del Estado y criminales que desvía funciones básicas del Estado que son manejadas por criminales, y la gobernación para satisfacer intereses criminales.

En este artículo se hace un análisis detallado de las formas que reviste el Crimen Autorizado y se revisa el impacto de este fenómeno sobre el consenso y la legitimidad.

En esta revisión abordamos distintas formas de violencia y revisamos críticamente la existencia de una violencia legítima, porque al mezclarse con el crimen se distorsiona la legitimidad.

Palabras clave: Crimen Autorizado; crimen; legitimidad; consenso; México; corrupción.

\section{Abstract}

Authorized Crime is an association between criminals and certain areas of the state, which distorts the basic functions of the state and governance for criminal interests.

In this article we analyze the different forms of Authorized Crime and revise this phenomenon's impact on consensus and legitimacy.

We consider different forms of violence and critically review the existence of legitimate violence, at least, because legitimacy is distorted when it blends with crime.

Keywords: Authorized crime; crime; legitimacy; consensus; Mexico; corruption. 
No es un fenómeno exclusivo de Guerrero. Desde hace más de 10 años hay una infiltración de la delincuencia organizada en las instituciones, no sólo en la burocracia, en los jueces o los procuradores, sino también en los partidos políticos. Estos les abrieron las puertas para financiar candidaturas; luego el narco se dio cuenta de que ellos podían ser el alcalde, el diputado y hasta el gobernador.

Rogelio Ortega. Gobernador de Guerrero, México 2014.

\section{Introducción}

La ola criminal que arrasa a México y otros países no puede explicarse con conceptos policíacos convencionales, ni considerarse como un fenómeno que se presenta en las márgenes de la política o del cumplimiento de valores morales. Aunque la corrupción es una variable importante del fenómeno, reducir el análisis a ésta es insuficiente para entender lo que sucede. El tema del narcotráfico esta ocupando un valor central en el discurso político e inclusive se le asocia con el de terrorismo como sugiere Tokatlian,(1) sin embargo, la mayor parte del debate para la erradicación sigue siendo convencional. En este artículo revisamos el concepto de crimen autorizado, asumiendo que tiene una condición estructural que supera a una simple anomalía o desajuste coyuntural.

En esta revisión abordamos distintas formas de violencia y revisamos críticamente la noción de la existencia de una violencia legítima como componente de un régimen democrático, porque, por lo menos, al mezclarse con el crimen la legitimidad se distorsiona.

\section{Definición de crimen autorizado}

Crimen autorizado postula que la actividad criminal como la que lleva a cabo el crimen organizado no se da en el vacío sino que opera en conjunto y asociado con personal del Estado: policía, funcionarios públicos y jueces, en uno o mas niveles de gobierno (municipal, estadual, federal).(2)

Entre las múltiples formas de asociación encontramos: policías trabajando como sicarios, trabajando para los carteles, trabajando como cartel; fuerzas del orden y legales protegiendo actividades criminales como la venta de drogas y mercancías robadas, militares trabajando en complicidad con criminales, funcionarios aprobando o estimulando violaciones a la ley (tabla I). Buscaglia encuentra el fenómeno, pero supone que es un proceso de penetración del estado por los criminales, descrito en cinco niveles y asumiendo que las mafias luchan por capturar al Estado, mientras que nosotros sostenemos que la peculiaridad es la asociación que evita os 
vacíos de poder.(3)

Muchas actividades criminales florecen, y de hecho no pueden ocurrir, sin la complicidad de autoridades municipales, estaduales o federales, ya sea separadas o en conjunto y ocasionalmente compitiendo entre sí. En algunos casos todas las autoridades trabajan en conjunto con los criminales, en otros casos diferentes autoridades se asocian con distintas facciones criminales o carteles, elevando a cuestión de Estado el enfrentamiento entre criminales, lo que transforma el conflicto, la confrontación y la violencia, especialmente porque hay una confrontación interna en el Estado para que ciertas facciones, grupos o individuos (públicos o privados) se beneficien de la asociación con los criminales. Encontramos asociaciones complejas entre empresarios, líderes sociales, políticos y criminales que mezclan actividades legales con la criminalidad, lo que dificulta encontrar la línea que separa lo legal de lo ilegal o los diversos grados de la ilegalidad. Un ejemplo es el lavado de dinero. Hay empresas que lavan dinero que evadieron para no pagar impuestos, mientras que hay empresarios que lavan dinero de los carteles; se puede considerar que el lavado puede tener el mismo impacto fiscal, pero las distintas acciones no tienen la misma consecuencia criminal.

Los gobiernos se concentran en manejar información sobre índices delictivos y criminales, lo que puede ser una falsa señal que oculta el verdadero poder del Crimen Autorizado, que llega a beneficiarse con la expansión de los intereses criminales para conseguir ganancias económicas "legales" derivadas de actividades criminales. La asociación de negocios legales con los criminales, lleva inclusive a la apropiación territorial sin molestias judiciales de propiedad de la tierra, para desarrollar negocios privados utilizando recursos naturales.(4) Esta condición forzosamente cambia la presunción de responsabilidad de elementos del crimen organizado extendiéndola hacia el Estado que es corresponsable.

La asociación entre el crimen y el Estado llega estrecharse al grado de parecer una simbiosis, que incluye el consentimiento estatal de actividades criminales, que los funcionarios volteen la vista a otro lado ante la acción criminal, o que los funcionarios actúen como criminales. El Crimen Autorizado es una condición estructural que ayuda a arraigar socialmente al crimen (5) y dificulta la lucha contra las actividades criminales, porque la batalla deja de ser una cuestión policíaca para adquirir connotación política. Podemos sospechar que hay gobiernos que no atacan con fuerza a los criminales por temor a una inestabilidad social y política mayor.

La corrupción eventualmente puede atacarse con prácticas y decisiones institucionales, pero el Crimen Autorizado involucra una co-dependencia entre las fuerzas del orden, diversas instancias de representación y de gobierno con el crimen. La corrección de esta condición es complicado porque se ha convertido en modus vivendi de ciertas fuerzas del Estado y ha creado una cultura de protección estatal a los criminales; atacarlo conlleva un elevado costo 
político, elevados índices de fracaso debido al efecto inhibidor de las complicidades, un cierto deterioro institucional y una percepción societaria que reduce la legitimidad del gobierno.

La asociación crimen-gobierno explica porque muchas acciones de las fuerzas del orden (6) son poco efectivas, ya que entre las anomalías generadas se encuentra: el filtrado a los criminales de información sobre las operaciones de la policía o los militares, lo que le permite a los criminales evadir los operativos contra ellos (7) o manipularlos para dirigirlos contra sus enemigos; facilita el éxito de las actividades criminales, por ejemplo, la ordeña de gasoductos en México que supuestamente cuenta con apoyo de técnicos de la empresa estatal PEMEX y la protección de autoridades a los criminales que negocian con la gasolina (8) vendida en parte a gasolineras.

$\mathrm{Ni}$ la actividad criminal ni la guerra contra el crimen crean vacíos, tampoco una seria confrontación con el Estado, por el contrario, se crea una condición política que distorsiona y suplanta las funciones básicas del Estado (9) y oprime a la sociedad de una forma novedosa porque se legitima la violencia; la resistencia societaria se ve limitada para confrontar la agresión, muchas veces lo hace pasivamente, porque su resistencia implica confrontar al Estado, como ha sucedido con las fuerzas de autodefensa civiles en varios Estados de la República mexicana. La sociedad se retrae optando por la inacción ante la distorsión de procedimientos formales, como integrar mal una averiguación judicial para proteger a los criminales que son detenidos, o la protección a los miembros del Estado que violan la ley;(10) en casos extremos se organiza para enfrentarse al gobierno. Las formas de violencia brutales de los criminales introducen miedo buscando paralizar a la sociedad, esto impacta negativamente las denuncias contra el crimen porque la gente piensa que los criminales y la policía son lo mismo.(11) Se crea una situación dónde se mezclan las violencias legítima con la criminal, legitimándose la criminal; y donde se ha estropeado la comunicación entre el Estado y la sociedad, dificultando la gobernación (12) y afectando el Estado de derecho, llegando al punto de hacerlo desaparecer.

Aportando a las complicaciones que genera esta combinación de violencias, Arendt (13) dice: "En un contexto de violencia contra violencia la superioridad del gobierno ha sido siempre absoluta pero esta superioridad existe solamente mientras permanezca intacta la estructura de poder del gobierno -es decir, mientras que las órdenes sean obedecidas y el Ejército o las fuerzas de policía estén dispuestos a emplear sus armas". Aquí está la gravedad del crimen autorizado, porque la violencia de los criminales se vuelve simbiótica con la estructura de poder y hace que la violencia legítima funcione de una manera perversa. La estructura de poder se pone al servicio del crimen, elevando lo que Hermosa (14) denomina como la región demoniaca de la naturaleza humana, a un nivel muy peligroso, porque como veremos más adelante, el monopolio de la violencia legítima adquiere una racionalidad 
criminal.

En contraste con nuestra definición es conveniente considerar la de Mixon (15) que se refiere a crímenes autorizados (en plural) como aquellos crímenes autorizados por el Estado y que legalizan los asesinatos, ahí los que matan no son criminales, porque están cobijados por la violencia legítima, esto en parte ha dado lugar a un fenómeno preocupante de brutalidad policíaca; para Mixon la obediencia juega un rol mayor, lo que nos lleva a considerar el conflicto entre obediencia y ética.

Uno de los casos clásicos de crímenes autorizados es la guerra, pero quién lo llevó al extremo del horror es la organización industrial del asesinato de millones perpetrado por los nazis.(16) Mixon discute en extenso porque debe haber un límite ético para que los perpetradores de crímenes autorizados no puedan argumentar en su defensa que simplemente obedecieron órdenes, especialmente sabiendo que sus crímenes violentaban valores morales; desde esta perspectiva Hannah Arendt concluyó que Eichman representaba la banalidad del mal porque el se definía como un burócrata que cumplió órdenes, lo que no reduce el mal de los crímenes autorizados ni el rol bestial que él jugó junto con aquellos que sostuvieron ese esfuerzo de exterminio, ni tampoco la complicidad por omisión de millones de ciudadanos. La distorsión consiste en que el individuo se comporta como delincuente que busca evadir la responsabilidad porque alguien más dio una orden.(17) La obediencia inicial de los asesinatos brutales, sean selectivos o masivos y limpiezas étnicas, lleva a los perpetrantes a una espiral de violencia irracional que adquiere expresiones brutales e inhumanas, como se muestra en prácticas bestiales como la decapitación, el desmembramiento, o lanzar cuerpos a la vía pública para que los mensajes criminales sean recibidos por múltiples receptores, ya sean otros criminales o la sociedad que se aterroriza, porque uno de los objetivos es infundir terror, ya que este paraliza. La obediencia se relaciona con la jerarquía: "Obedience means doing things, not because of personal desire, wish or motive, but because someone tells us to... not because of a personal relationship but because of a status relationship -a relationship of subordination to a superior status with the authority or command'.(18) Un criminal (sicario o asesino a sueldo) sabe que comete un crimen pero esta cumpliendo una orden,(19) es obediente, lo que no lo hace inocente, lo mismo sucede con guardaespaldas, militares o policías que saben que violentan valores, especialmente aquellos que a sabiendas violan la ley, ellos son los que configuran el crimen autorizado.

...su vértigo criminal no se detiene con los muertos recién asesinados, sino que, a partir de ahí, encandilados por la matanza, los asesinos prosiguen su tarea homicida sin desmayo. Y no es solo, creemos, que su actual posición dominante les haga sentir la conciencia de impunidad a flor de piel, la cual, por cierto, se advierte en el hecho de aducir fáciles explicaciones fantasma para justificar el asesinato de 'aquellos de sus 
conciudadanos a los que consideraban enemigos'.(20)

Estar abajo en la línea de mando no excusa a nadie por cometer crímenes, porque como sostiene Mixon, es un elemento central la posibilidad de resistirse a cumplir una orden, aún sabiendo que hay un castigo por no cumplir. Cuando el sicario es agente de las fuerzas del orden, o que trabaja para los criminales en diferentes capacidades, sabe con certeza que viola la ley y que hay consecuencias legales, y no lo excusa de ninguna manera el que obedezca órdenes de su superior, en el cartel o en el comando legal, que en algunos casos, como sucedió en Ciudad Juárez (21) en los 1980s, ambos roles caen en la misma persona.

\section{El Estado y la violencia}

El Estado está formado por una serie de instituciones de naturaleza legal y política, que incluyen el aparato legislativo, de formulación de cursos de acción y decisión política, administración pública, aparato represivo y un sector económico.

La razón del Estado es la intervención en varias vertientes: Económico, ideológico, social, arbitraje, represión. La función de la intervención es la preservación del sistema controlando el conflicto, reduciendo tensiones que puedan atentar contra la estabilidad, o que pongan en riesgo la continuación del sistema o sus elementos estructurales básicos, que en el sistema capitalista es la propiedad privada. Dentro de la intervención el Estado tiene la capacidad de afectar ciertas partes de la propiedad privada, pero nunca atentará contra la esencia y naturaleza de ésta.

Para reducir el impacto de los conflictos, la forma de intervención difiere dependiendo de su naturaleza y de la correlación de fuerzas,(22) aunque la represión es una constante. El uso de la represión para confrontar la disidencia, luchar contra el mal, o para castigar, depende de las condiciones internas, aunque se puede aventurar la tesis que a mayor libertad las formas represivas tienden a ser más sutiles y menos violentas, mientras que en el totalitarismo la represión anula la libertad. Con el Crimen Autorizado se coarta la libertad mientras se mantiene un discurso democrático.

Todos los gobiernos intervienen económicamente, en muchos países el Estado controla corporaciones que producen bienes y productos básicos como el petróleo (PEMEX en México, PDVISA en Venezuela, Petrobras en Brasil, ARAMCO en Arabia Saudita), en otros controla la producción de ciencia y tecnología (los laboratorios nacionales y la NASA en Estados Unidos, CNRS - El Centro Nacional para la Investigación Científica en Francia). 
Ideológicamente en la mayoría de los países la educación es gratuita y hasta obligatoria, está controlada por del Estado y es el medio para reproducir la ideología, lo que se considera violencia estructural.

La reproducción del sistema es dinámica, mientras el Estado tiene larga permanencia los gobiernos cambian. En la democracia el gobierno cambia con regularidad, no así en los sistemas dónde el Estado y el gobierno se fusionan de tal manera que su destino es casi el mismo. Este fue el caso de la Unión Soviética que se disolvió en 1991 después de intentar reformas profundas en la economía y la política. En todos los casos el Estado asume el monopolio de la violencia legítima, ejerciéndola con distintos grados, así las democracias reprimen para eliminar el conflicto que afecta la armonía democrática, y las dictaduras reprimen para eliminar a la disidencia que cuestiona la falta de libertad. Ambos piensan que sus actos son legítimos.

Es posible que el Estado tenga gobiernos de naturaleza contradictoria. En el caso de Chile el Estado capitalista vivió una transición de un gobierno democrático hacia una dictadura militar y de vuelta a la democracia electoral.

Un tema relevante es identificar que el Estado recurre a extremos de represión, desde campos de concentración hasta limpiezas ideológicas y eliminación de disidentes. ¿Por qué dentro de las normas democráticas el Estado autoriza crímenes?, lo que sucede según Mixon básicamente durante la guerra, pero la guerra puede ser interna distorsionándose la imagen del enemigo o del mal, considerándose como el mal a disidentes enfrentados al gobierno, en este acto represivo el gobierno suplanta a la nación. Las guerras sucias en América Latina se enfocaron contra la disidencia ideológica. Una primera lección es que mientras el gobierno es temporal el Estado tiene una existencia más prolongada; mientras el fin del gobierno usualmente es la elección siguiente, el fin del Estado puede ser una revolución,(23) de ahí que el gobierno asuma como enemigos a los que plantean una opción de cambio radical, aunque preserve al Estado y contra éstos se dirige la violencia y los crímenes autorizados.

Para cumplir con su función esencial que es la reproducción del sistema, el Estado interviene en los elementos societarios básicos y sus fuentes de conflicto, de tal suerte que reduzca o elimine las inestabilidades, neutralice huelgas, motines o sublevaciones y hasta confrontaciones de grupos sociales específicos, véase al respecto el análisis de Arendt (24) sobre los movimientos estudiantiles de los 1960s.

Políticamente, una forma de legitimar la represión es invocar la Razón de Estado, que implica salvaguardar la salud del Estado como garante del bienestar general, aunque con frecuencia se distorsiona a favor del gobierno y los intereses específicos que promueve el Estado, en lugar de proteger a la estructura social como un todo, o sea, a todas las clases sociales; de aquí se desprende que el Estado no es el todo social, sino la superestructura que 
lo domina. Idealmente, el Estado por medio de todas sus instituciones debe garantizar relaciones armónicas para asegurar una continuidad estable, sin embargo, eso lo logra con opresión y represión.(25)

El componente básico del sistema capitalista es la propiedad privada y las relaciones sociales alrededor de ella, es por esto que la intervención en el neoliberalismo, que ideológicamente (26) aboga por la no intervención del Estado asegura esta intervención para introducir cambios económicos, y la represión se concentra en el ataque a los líderes opositores, ya sean defensores de los derechos humanos, el ambiente o grupos sociales desprotegidos. Los impuestos son un mecanismo de intervención, al igual que la regulación de recursos naturales. De nuevo la NASA es un buen ejemplo, promueve las metas científicas y tecnológicas estratégicas de Estados Unidos y es una corporación pública, por medio de la cual muchas universidades reciben apoyo para su investigación orientada a reforzar los objetivos estratégicos, y el sector privado transforma la ciencia en tecnología comercial. También juega un papel importante en el terreno económico y político por medio de su interacción con el complejo bélico y de producción de armamentos, ayudando a delinear la estrategia mundial política y económica de Estados Unidos. Un redondeo exitoso en la función del Estado.

El estudio sobre el Estado puede realizarse desde diferentes niveles de abstracción. Un nivel es la relación entre la sociedad y el Estado donde el gobierno juega un papel central, al igual que lo hacen diferentes niveles de intermediación societaria, en este acercamiento la aceptación social es muy relevante, y dos conceptos son centrales: consenso y legitimidad. Siguiendo a Weber podemos considerar que el origen de la legitimidad esta basado en la construcción del consenso, que se origina en un acto legal (elecciones). Independientemente del resultado electoral, mientras las partes lo acepten será legítimo, porque implica aceptar la legalidad del hecho político, la elección. Suponemos que si los partidos que contienden aceptan los resultados, la sociedad en general hará lo mismo. Se genera un conflicto si un partido político rechaza los resultados debido a ilegalidades, o si un segmento de la sociedad rehúsa aceptar los resultados electorales, lo que en ninguno de los dos casos necesariamente deslegitima al gobierno; la incapacidad del gobierno o el Estado para resolver el conflicto, puede generar distintas soluciones que pueden llegar hasta el golpe de Estado.(27) El rechazo de los resultados electorales impacta al gobierno y no necesariamente al Estado y las consecuencias políticas más amplias dependen de la acción política (cualquiera que sea su intensidad) de los grupos sociales agraviados y de los grupos hegemónicos, por lo que podemos concluir que el rechazo tiene un peso político relativo.

Seymour Lipset (28) considera a la legitimidad como la aceptación social del gobierno, lo que implica la posibilidad de que un gobierno cuyo origen es ilegal e ilegítimo, como por 
ejemplo el derrocamiento del gobierno, sea aceptado por segmentos importantes de la sociedad al ser eficaz y eficiente, en este caso, la represión tienen una funcionalidad legitimadora. De nuevo conviene aludir a la diferenciación de diversos actores políticos y sociales.

Hemos introducido un elemento de relatividad, porque ni los sistemas sociales ni los políticos son homogéneos; no podemos considerar que toda la sociedad acepta o rechaza al gobierno, aún los derrotados en la elección y que aceptaron los resultados electorales, llegan a oponérsele activamente al gobierno, es el caso de los republicanos ante Obama en Estados Unidos que buscaron con denuedo una parálisis en diversas áreas; o el triunfo de la oposición en Venezuela en 2015, cuya oposición no necesariamente deslegitima al gobierno aunque buscan deponerlo por la vía jurídico-política. La oposición también debe relativizarse, no es lo mismo rechazar proyectos del gobierno federal como hicieron gobernadores republicanos, a la intención de la oposición venezolana de revocar el mandato de Maduro. Es posible que algunos grupos le declaren la guerra al gobierno lo que según Sprinzak (29) configura una crisis de legitimidad, aunque no es el todo social el que de-legitima al gobierno; por otro lado, la aceptación de los grupos hegemónicos puede ser suficiente para apoyar al gobierno y darle la capacidad de usar el monopolio de la violencia legítima para neutralizar a los grupos que rechazan al gobierno, lo que neutraliza relativamente a la de-legitimación, aunque esta se generalice entre amplios segmentos sociales.

En este punto debemos cuestionar si esa violencia es o puede ser legítima y para quién, tema que configura un debate importante para confrontar la noción Weberiana del monopolio de la violencia legítima. Los crímenes autorizados de Pinochet en Chile alcanzaron a desaparecer a 10.000 personas, muchos de los cuales pertenecían al gobierno derrocado y se oponían al acceso violento al poder de los militares, mientras que la clase dominante, con ayuda exterior, aprobó la masacre, ya que a cambio se revirtieron los cursos de acción política económicos implantados por el gobierno de Allende legítimamente electo. Para las personas que le aplaudían a Pinochet en los restaurantes él era legítimo, para los parientes, amigos y compañeros de los muertos y desaparecidos no lo era, pero el primero de éstos grupos dominaba el espacio económico y político.(30) En el mismo cuadro cabe Pol Pot, los campos de concentración de Stalin y Hitler, los campos de re-educación de Mao, la guerra sucia mexicana. Algunos sistemas pueden evolucionar de un gobierno elegido democráticamente hacia un régimen totalitario como es el caso de los nazis en Alemania, donde los crímenes autorizados llegan a nivel de tragedia humanitaria mundial.

Si el análisis parte del uso de la represión, debemos ser cuidadosos al interpretar el silencio de los reprimidos, que difícilmente puede ser considerado como una condición de 
aceptación. Su silencio no le crea consenso a las acciones y decisiones del gobierno. En este sentido el viejo adagio de que El que calla otorga tiene nula utilidad.

La violencia no es solamente física como veremos más adelante, también la hay estructural, simbólica y cultural y se manejan como legitimas, porque su función es la reproducción del sistema, incluyendo sus desigualdades e injusticias. El gobierno no es el único que tiene acceso a la violencia, la tienen también los individuos, grupos opositores y grupos criminales, lo que lleva a la polémica sobre la segunda enmienda de la Constitución (31) en Estados Unidos que autoriza la posesión de armas, y el hecho que en ese país se registre un número muy elevado de muertos por armas de fuego.(32)

Volviendo al análisis de más arriba, considerando que la legitimidad no requiere de una aceptación absoluta, la reproducción del sistema se justifica por los grupos y clases sociales interesados y beneficiados, incluida la burocracia, de ahí que la injusticia -económica, social y jurídica- pase a un segundo plano en el debate. No esta en cuestión el porcentaje o dimensión de la parte de la sociedad que legitima o no al gobierno, porque no todos los actores sociales tienen el mismo peso político o capacidad de legitimación.

Se requiere otra precisión. La legitimidad se refiere al gobierno no al Estado porque este no la requiere, ya que su racionalidad está en el largo plazo y esta relacionada a un proyecto clasista que se ubica por arriba de una aceptación temporal, este proyecto puede ser apoyado como vimos, por gobiernos legítimos o ilegítimos, condición también cambiante. No obstante lo anterior, una crisis de legitimidad, aunque sea entre pequeños grupos, puede destruir al Estado, es el caso de las revoluciones (33) Cubana, China, Rusa, pero este es otro tipo de proceso político.

La intervención gubernamental se sostiene en funciones específicas, que en ciertos casos son monopólicas, por ejemplo: imponer impuestos, control de las fuerzas armadas y las fuerzas del orden, aplicación de la ley y de los castigos. Por esto Weber lo consideró un monopolio de la violencia legítima, que no deja de ser un concepto autoritario, porque le da al Estado la capacidad de imponer su visión por la fuerza, y someter a la oposición societaria; en palabras de Arendt "el poder corresponde a la esencia de todos los gobiernos, pero no así la violencia".(34)

Dada la variedad de violencias existentes sería conveniente hablar de fuerza en lugar de violencia, pero tampoco sobre la fuerza el gobierno tiene monopolio, porque hay muchos factores que tienen y usan la fuerza, desde el criminal que asalta a una persona, hasta las milicias que ocupan terrenos públicos o agreden a grupos sociales, como hizo el Ku Klux Klan contra los negros. Pero puede haber una contra intervención gubernamental deliberada y pensada para generar intencionalmente un gobierno inefectivo, que genera como dice Buscaglia (35) vacíos de controles: judiciales, patrimoniales, controles políticos de la 
corrupción y controles sociales para la prevención del delito. En este caso nos encontramos ante una ineficiencia planeada.(36)

El monopolio de la violencia legítima se convierte en el monopolio del miedo legítimo y del terror legítimo y en esto el Crimen Autorizado cumple un papel fundamental. Refiriéndose a la prohibición de tocar narcocorridos en México, Olvera (37) dice: "no se inscribe en un dilema político en el que el Estado opta por obtener el monopolio para lucrar con el miedo". Voltaire dice: "las leyes se promulgan para socorrer a los ciudadanos y para intimidarlos".(38) Weil (39) agrega "Even this clownish uniform created fear and made people avoid him or doff their hats respectfully to him: a uniform meant power... But power however conditional, however tenuous, still inspires fear". Cuando el monopolio del miedo y el terror se mezcla con el crimen autorizado, la sociedad queda indefensa e inerme porque los elementos legitimadores, la idea e instituciones básicas que se crearon para defenderla, incluida la violencia legítima, se usan contra ella.

Uno de los principales atributos del Estado es su capacidad para definir al mal;(40) el mal pone en peligro al sistema, luego entonces el Estado lucha contra él para defender a la sociedad; el problema es que con frecuencia el gobierno es el mal y deja de defender al interés general promoviendo el interés de los pocos y se defiende a si mismo contra la sociedad, por eso la Razón de Estado se pervirtió y el uso de la violencia legítima se usa contra la sociedad, es el caso de la represión de distintas formas de resistencia social como huelgas, invasiones de tierra o protestas callejeras. Con el Crimen Autorizado el problema se eleva exponencialmente, ya que los instrumentos para la defensa del interés general y la lucha contra el mal, que deberían ser legítimos, se usan para promover intereses criminales.

Cuando el Estado define al mal tiene la oportunidad y la autoridad legítima de movilizar a la sociedad para luchar contra él, es el caso de la guerra, por ejemplo, cuándo los dictadores militares argentinos le declararon la guerra a Inglaterra por las islas Falkland, o cuando las élites políticas mexicanas llaman a tolerar la presencia militar en las calles, aún frente a la evidencia de violaciones masivas de los derechos humanos por soldados, marinos y policías.

Recordemos que según Mixon durante la guerra los crímenes autorizados legalizan el acto de matar, el soldado no es homicida, pero cuando se trata de Crimen Autorizado en el sentido que lo hemos definido (en singular), el Estado legitima la violencia personal y la combina con el miedo y terror legítimos para aterrorizar (41) y paralizar a la sociedad y dejarla inerme ante los criminales, los actos criminales de los agentes del orden dejan de serlo jurídicamente.

\section{Crimen Autorizado y el Estado}


Cuando el Estado cede ante el crimen, ya sea por la asociación con los criminales o porque partes del mismo trabajen para los criminales, convierte la legitimidad de la violencia en el uso legitimo del Crimen Autorizado. "Entre las peculiaridades de nuestra época figura también la irrupción masiva del crimen en los procesos políticos... nos la vemos con un estilo de hacer política que es criminoso en sí mismo".(42)

Hay una gran diferencia entre lo público y lo privado en este sentido. Cuándo un policía o un político viola la ley, como individuo, se puede considerar una cuestión ética porque viola valores morales, pero cuando está investido con autoridad, su acto se convierte inevitablemente en una cuestión política (43) porque atenta contra la moral social y política y contra la confianza que la sociedad le confirió al Estado; ya no es un ciudadano violando la ley sino un miembro del Estado cuya responsabilidad es defender y proteger a la ley (44) y a la sociedad, así entra en juego el ejercicio del poder, que de acuerdo a Arendt "is about command, dominate".(45) El individuo está obligado a obedecer a la autoridad, pero si el investido por la autoridad ataca a la sociedad, nos encontramos con una distorsión del consenso y la legitimidad, se altera la corresponsabilidad del principio de autoridad y del ejercicio honesto del poder; la confianza es reemplazada por el miedo y el terror legítimo.

La violencia se asocia con conflicto y dominación. Conviene aquí recuperar el concepto de Violencia Estructural de Galtung que se refiere a "social injustice, blueprint to bring people into subordination" y nosotros agregamos sumisión, "the object might be persuaded not to perceive this at all'.(46)

Todos los sistemas tienen diferentes tipos de conflicto, y en todos los sistemas existe una cierta cantidad de violencia; la violencia estructural genera cierta estabilidad porque está asociada con el Estado, y como sostiene Galtung, con la producción y reproducción de la ideología como función del Estado.

Hemos mencionado que el Estado consiste de una serie de instituciones enraizadas inicialmente en el pueblo, creándose una relación dialéctica entre el Estado y la Sociedad, dónde idealmente debería prevalecer cierto equilibrio, sin embargo, la realidad demuestra que el Estado, como considera Engels,(47) se divorcia de la sociedad poniéndose por encima de ella, y una de las expresiones del divorcio es el uso de la violencia más allá de lo legítimo, si es que, contradiciendo a Weber, se puede considerar legítima la violencia contra la sociedad.

La Violencia Estructural prevalece por su relación dialéctica con la reproducción del sistema, y en este sentido los crímenes autorizados que define Mixon son un componente estructural de esa relación, y es por eso que el Crimen Autorizado, que también incide en la violencia estructural, tiene un impacto rotundo en ambos niveles.

La dominación está relacionada con la obediencia, "obedience plays a major role in the everyday life of people who fancy themselves autonomous and independent".(48) Los 
ciudadanos obedecen los mandatos del gobierno y no se resisten ante los crímenes autorizados,(49) de hecho muchos los toleran y apoyan, lo que explica en gran medida el poder y la efectividad del Crimen Autorizado que llega a camuflagearse como crímenes autorizados y por lo tanto como violencia legítima. Una persona se detendrá siguiendo la orden de un policía y obedecerá para subirse a una patrulla, sin saber que el policía trabaja para un cartel (50) y que posiblemente lo llevan a ser torturado, asesinado y desaparecido.

Un caso interesante y emblemático sobre violencia estructural se refiere a las solicitudes de asilo político en Estados Unidos, dónde los solicitantes que buscan protección en un puerto de entrada al país son encarcelados.(51) El caso de Efraín Chávez Maldonado es ilustrador, su hermano gemelo fue asesinado por la policía en Ciudad Juárez y escapó de México buscando protección en Estados Unidos. Tan pronto entró al país fue encarcelado bajo el supuesto que aún siendo víctima era un riesgo para la sociedad, duró encarcelado por casi dos años y medio en contra de diversas convenciones internacionales y de la constitución política de Estados Unidos. La juez de migración le negó el asilo bajo la premisa de que la policía estatal que asesinó a su hermano no es el "Estado nacional",(52) este es un análisis y conclusión perversa para negar el asilo, o ignorancia extrema sobre cuales son las instituciones del Estado, pero cualquiera que sea el caso, actuó con violencia en contra de la víctima; el juez que recibió la apelación, que anteriormente fue oficial de migración ordenó corregir la decisión, sin embargo, ella insistió en la decisión; mientras el caso se apelaba por segunda ocasión, la víctima veía violados sus derechos constitucionales con una detención prolongada. Esta forma de manipular la ley es violencia estructural y pulveriza los derechos de los individuos.

La violencia estructural también se refiere a la desigualdad e incluye la estructura social y la estratificación. Mixon determina que todas las sociedades son desiguales mientras que nos hacen creer que todos somos iguales y libres (ideología), pero al tener que obedecer, nuestra libertad se limita. Bakunin (53) sostiene que la libertad no puede ser relativa, o hay o no hay; la gente es libre o no lo es, no hay grados de libertad y la manipulación y limitación de la libertad es violencia estructural.

Muchos análisis se basan en desigualdades: brechas sociales, políticas y económicas; es posible pensar que estas desigualdades pueden llevar a violencia estructural y personal, de hecho pueden llevar, en la medida que se mezclen con otro tipo de violencias y conflictos, a un estado fallido. "The violence is built into the structure and shows up as unequal power and consequently as unequal life chances".(54) Estas brechas son una fuente de conflicto, que para suprimirlo, el Estado confronta por medio del monopolio de la violencia legítima y crímenes autorizados, especialmente aquellos conflictos que ponen en peligro al sistema, y en el proceso se atenta contra la libertad y la justicia y se abre la posibilidad de niveles superiores 
de violencia y conflicto. De esta manera el Estado pisotea las normas de la justicia que tiene la función y obligación de imponer y respetar y la lucha por la supervivencia de libertad y justicia se convierte en heroísmo.

\section{La categoría de Violencia Estructural:}

"It refers to a form of violence wherein some social structure or social institution may harm people by preventing them from meeting their basic needs. Institutionalized adultism, ageism, classism, elitism, ethnocentrism, nationalism, racism, and sexism are some examples of structural violence. According to Galtung, rather than conveying a physical image, structural violence is an avoidable impairment of fundamental human needs. As it is avoidable, structural violence is a high cause of premature death and unnecessary disability. Because structural violence affects people differently in various social structures, it is very closely linked to social injustice. Structural violence and direct violence are said to be highly interdependent, including family violence, gender violence, hate crimes, racial violence, police violence, state violence, terrorism, and war"'.(55)

Wikipedia incluye la violencia de Estado y la policía, lo que muestra el error típico de no considerar a las fuerzas del orden como un componente principal del Estado; igual hace con el terrorismo, que puede ser privado o del Estado, este último se efectúa frecuentemente por medio de crímenes autorizados, lo que complica el análisis de la violencia estructural, especialmente si llevamos el análisis a la escena internacional. Algunos países ordenan crímenes autorizados (terror) en otros países (56) sin declarar la guerra, o cometen esos crímenes contra sus enemigos, en terrenos de un país que no es parte de esa guerra. 


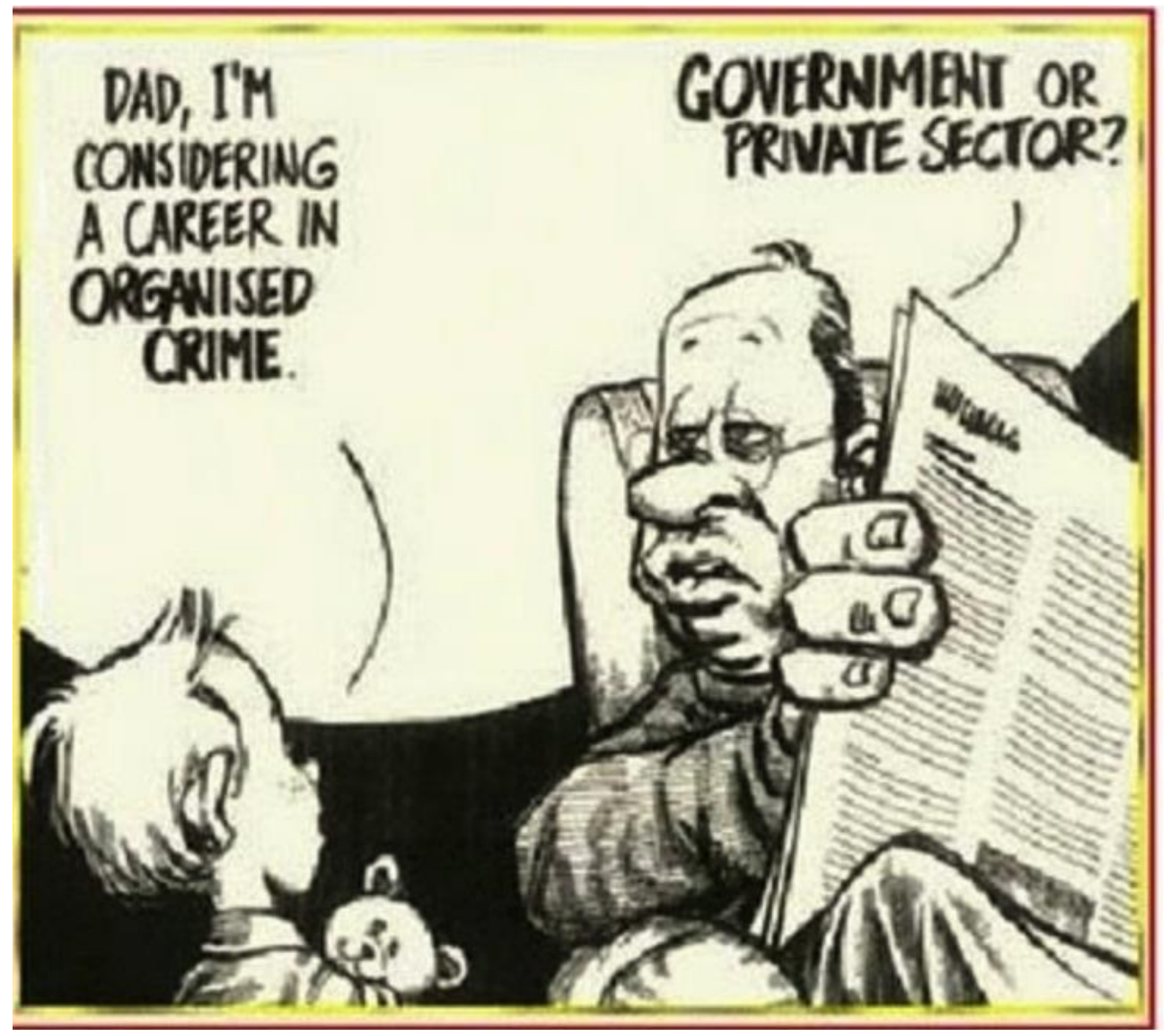

La idea de evitabilidad de Galtung refuerza la noción que el concepto Weberiano de monopolio de la violencia es un concepto autoritario; la función represiva es inherente al Estado y por lo tanto no es evitable, al responder al interés de unos pocos, ya sea una clase social o una parte de ella (oligarquía) difícilmente podrá contar con consenso;(57) los crímenes autorizados responden a una forma peculiar de manejar el conflicto y no necesariamente ayudan a promover el interés general, y muchas veces refuerzan las desigualdades e injusticia.

Relativiza la legitimidad la supuesta predisposición del pueblo (consenso) para sufrir represión o que la violencia se ejerza sobre sus oponentes, especialmente porque legitima la violencia estructural que reproduce las desigualdades sistémicas; el hecho que esa violencia (la estructural y la legítima) se pueda ejercer sobre la gente independientemente de su aceptación, sugiere que no todos necesariamente aceptan el uso de la violencia legítima contra ellos o contra otros, aún cuándo tengan que obedecer;(58) el uso de la violencia contra los enemigos pasa por otras consideraciones morales, políticas y valorativas, aunque puede revertirse en contra de la sociedad. En este contexto el Crimen Autorizado es la peor forma de violencia ejercida sobre y contra la sociedad, ya que la asociación entre los criminales y el 
Estado transforma la legitimidad de una forma perversa. Es el caso de la violencia que Estados Unidos ejerce en contra de los migrantes y que ha permeado en contra de su sociedad, como por ejemplo, la restricción de las libertades amparadas por la Patriot Act.(59) La violencia física que puede incluirse en la violencia estructural restringe los movimientos y por lo tanto constriñe la libertad. Esta es también violencia sobre el cuerpo y el alma, que incluye mentiras, amenazas y adoctrinamiento, lo que nos lleva al terreno de la ideología, la que es manipulada por el Estado e impuesta sobre el individuo, y esto incluye la confrontación contra ideologías alternativas.

La Violencia Estructural implica una relación dialéctica con la violencia personal. La Violencia Estructural produce injusticia social y "gross social injustice is maintained by means of highly manifest personal violence".(60) Algunas formas de violencia personal pueden ser una respuesta a la Violencia Estructural, pero podrá ser legitimada solamente si el grupo derrota al gobierno o al Estado.(61) La meta de la Violencia Estructural es reproducir el sistema y no necesariamente eliminar la violencia personal, esta violencia que incluye formas alternativas de organizaciones violentas como: milicias, ejércitos privados, gangs, mafias, etc., deben ser neutralizados para prevenir que ataquen al sistema, aunque hay muchos ejemplos sobre como los ha usado el Estado para satisfacer el interés de unos pocos: la asociación del Estado en Estados Unidos con la Mafia italiana para luchar contra los fascistas, la asociación con los carteles de la droga para luchar contra los sandinistas en Nicaragua, la tolerancia de las milicias para patrullar la frontera entre Estados Unidos y México. En todos los casos esta asociación se ha revertido en contra de la sociedad y el gobierno, resultando ruinosa para la democracia, nociva para la salud pública porque ha engendrado carteles muy poderosos que entre otras cosas impulsan adicciones, producen matanzas masivas y fosas clandestinas que contaminan la tierra; tal vez no podría esperarse otro resultado de la mezcla entre los crímenes autorizados y el Crimen Autorizado.

Se supondría que la Violencia Estructural debe luchar contra la violencia criminal que incluye la violencia estatal: crímenes autorizados; pero no es así. Una pandilla genera violencia personal pero cuándo se mezcla con el Estado se convierte en Violencia Estructural y Crimen Autorizado, lo que complica el asunto tanto para la sociedad como para el gobierno, entre otras cosas, porque la violencia criminal se inserta en la Violencia Estructural y suplanta la racionalidad principal de la legitimidad, lo que orilla a la parte de la sociedad que se resiste, a actuar dentro de los márgenes de la legalidad y de las instituciones, para muchas veces ser derrotada, es el caso de las autodefensas en México que se enfrentan a los criminales y al gobierno, para encontrar una mano dura de ambos que en ocasiones actúa de manera concertada.

El Crimen Autorizado eleva la violencia personal hacia un nivel diferente de dolor y 
sufrimiento personal y social, entre otras cosas porque los agraviados no pueden encontrar ni consuelo ni justicia en las instituciones encargadas de protegerla; pero también lanza el tema a un nivel diferente de ganancia y beneficios personales y de grupo. Tómese el caso del Crimen Autorizado forzando el desplazamiento de gente de sus viviendas y propiedades, que facilita que ciertos intereses económicos, con la complicidad del Estado, se apropien de las propiedades que quedaron vacías. Cuando el conflicto y la guerra sirven para beneficiar a grupos privados, ya sean políticos, civiles o criminales, entonces se convierte en Violencia Estructural, aquí caben los que se beneficiaron por la guerra en Irak, entre los que estaban algunos amigos y asociados del Presidente George Bush.

Nos encontramos ante una paradoja, la Violencia Estructural contiene el monopolio de la violencia legítima que es un factor de estabilidad, de crímenes autorizados que son parte de la Violencia Estructural y que ayudan a fortalecer al Estado, y del Crimen Autorizado que se convierte en parte de la violencia Estructural. En la mente de la gente la faz del Estado se mezcla con actividades criminales, aunque ideológicamente se maneja como componente de la legitimidad, luego entonces, la simbiosis del crimen y el gobierno aterroriza a la sociedad y fuerza una sumisión perversa. Si la sociedad se resiste contra la Violencia Estructural y el Crimen Autorizado como ha sucedido en varias partes de México con las autodefensas, se arriesga a una respuesta violenta del Estado porque deslegitima, o por lo menos cuestiona, la Violencia Estructural.

La Violencia Estructural se acompaña de la violencia simbólica en todos los sistemas políticos; el grado de violencia -o tal vez sea más correcto decir fuerza- difiere según los tipos de sistema político, o según los tipos de democracia si acaso seguimos el enfoque de la calidad de la democracia, y los grados de resistencia social.

De acuerdo a Bourdieu (62) la Violencia Simbólica es una "violence exercised upon a social agent with his or her complicity". Este concepto debe considerarse junto con misrecognition, que quiere decir, "recognizing a violence which is wielded precisely inasmuch as one does not perceive it as such, ...order is deeply grounded so it needs no clarification" y por lo tanto se mueve entre la libertad y el constreñimiento. Es por eso que cuando el Crimen Autorizado suplanta a la mano represiva del Estado, cuando el policía pasa a ser sicario, la sociedad percibe el cambio sutil y actúa en consecuencia, cualquiera de las actitudes tiene consecuencias políticas.

La violencia esta acompañada de la Dominación Simbólica que se basa en una construcción social y estructural, con el Crimen Autorizado, una institución legítima que domina el sistema social es penetrada por una simbiosis entre funcionarios elegidos 0 designados con los criminales. Un ejemplo es una diputada en Sinaloa que promovía en el congreso la salida de las fuerzas militares del Estado que andaban a la caza de su protector, 
el Chapo Guzmán,(63) o un general cuya tarea era luchar contra los narcos pero actuaba con ellos.

El impacto de la violencia penetra la cultura generando Violencia Cultural que se refiere a los aspectos de una cultura que son usados para justificar o legitimar la violencia personal y Estructural.

"Cultural violence refers to aspects of a culture that can be used to justify or legitimize direct or structural violence, and may be exemplified by religion and ideology, language and art, empirical science and formal science... Cultural violence makes direct and structural violence look or feel 'right', or at least not wrong, according to Galtung. The study of cultural violence highlights the ways the act of direct violence and the fact of structural violence are legitimized and thus made acceptable in society. One mechanism of cultural violence is to change the "moral color" of an act from "red/wrong" to "green/right", or at least to "yellow/aceptable"'.(64)

Un ejemplo de éstos aspectos culturales se puede encontrar en la película El Crimen del Padre Amaro de Carlos Carrera (2002), dónde las relaciones de la iglesia con diferentes formas de violencia (guerrillera, criminal, de género) se veían como una situación "normalizada", o "lo que todos saben", suponiendo que "saber" implica una cierta forma de aceptación.(65) Estos aspectos culturales se pueden ejemplificar en la religión, ideología, lenguaje, arte, folklore (narcocorridos). Todas esas formas están influidas por el Estado y sirven al interés de la clase dominante, pero cuando el Crimen Autorizado suplanta distintas funciones del Estado se valida una forma distorsionada de dominación que puede afectar algunos intereses inmediatos de la clase dominante, aunque no amenaza la existencia del sistema, de hecho como mencionamos arriba, pueden llegar a coincidir los intereses de ciertos inversionistas con los de los criminales. Ciertos intereses criminales se "lavan" convirtiéndose en actores sociales respetables que asumen roles de dirección en distintas partes de la sociedad y la política, lo que genera más confusión entre la sociedad (66) mostrando las múltiples complejidades generadas por las asociaciones entre el crimen, la sociedad y la política.

\section{A manera de conclusión. Formas del crimen autorizado en México (67)}

Nuestra primera conclusión es que aunque la corrupción (68) es uno de los componentes principales del Crimen Autorizado, este fenómeno va mucho más allá de la corrupción.

Durante una charla de café de uno de los autores con tres personas, el alcalde de una ciudad fronteriza mexicana dijo: 
"- Saben, es la ley de plata o plomo. Si lo tomas, plata (riqueza entregada por los criminales), si no lo tomas, plomo (mueres). Yo no tomé.

- ¡Pero está vivo!"

Después de la frase un silencio rotundo cayó sobre la mesa, y desde entonces el alcalde muestra su desagrado con el imprudente. Todas las leyes, en tanto que leyes científicas, deben funcionar siempre, porque si funcionan solamente en unos casos, entonces no son leyes. Tenemos suficientes razones para pensar que en el caso del alcalde la ley funcionó, lo que por supuesto muestra que es corrupto, pero más que nada, que la máxima autoridad electa de la ciudad aceptó trabajar con los criminales, este es un caso de Crimen Autorizado.

La corrupción es el uso de la autoridad legítima y el poder para el beneficio de una persona o un grupo, y por eso es considerada como crimen en muchos países; en México las penas son muy altas pero rara vez se aplican y aún si un político es sancionado, las multas frecuentemente se evaden.(69) Bajo el Crimen Autorizado se distorsionan algunas de las funciones del Estado en una escala mayor, porque las consideraciones criminales de una persona o grupo se recubren con una falsa legitimidad atentando contra la democracia al inhibirse las leyes, llegando al extremo de generar aceptación social.(70)

México es uno de los países más corruptos del mundo, en 2014 Transparencia Internacional lo ubicó en el lugar 103 de 174.(71) Culturalmente los mexicanos parecen haber aceptado el hecho de que la corrupción determina su relación con las autoridades, ya sea sobornar a un policía, conseguir una licencia de manejar o permiso de construcción, ser vendedor ambulante, extorsionar a la sociedad o vender derecho de piso. De hecho, parecen haber aceptado la omnipresencia de la actividad criminal en todos los aspectos de la vida cotidiana.(72) Uno de los autores asistió a un funeral en Guadalupe, Chihuahua, un pueblo a unos 60 kilómetros al este de Ciudad Juárez, cuando entró al patio de la iglesia le explicaron: ésta es la iglesia vieja y ésta fue construida por el narco, como si la cuestión fuera quién construyó la iglesia y no hubiera conflicto con el origen del dinero.

Hace unos años estalló un escándalo en México cuando la jerarquía de la iglesia católica promovió un boicot contra la película El Crimen del Padre Amaro. ¿Qué enfureció a la curia? Algunos dijeron que se mostró a un cura que tuvo relaciones sexuales con una joven a la que convenció para que abortara al quedar embarazada, para otros su crimen fue poner sobre los hombros de la joven el rebozo que debía cubrir los hombros de la virgen, lo que parecía ser una transgresión; sin descartar la posibilidad del enojo por el manejo de los símbolos, creemos que la curia se molestó porque en la película se mostró a curas involucrados con criminales y guerrilleros, y la jerarquía no tenía problema en "lavar" el dinero que le donaban los criminales. Una iglesia donada por los criminales es tan santa como la erigida con el dinero del pueblo. Para un país con mayoría católica, el criminal se vuelve un buen samaritano, y por lo tanto, 
sus actividades criminales se excusan con el donativo apropiado.(73) Lo mismo se puede explicar cuando los criminales cobran "derecho de piso" a los vendedores ambulantes igual como lo hacen los inspectores del gobierno,(74) los criminales copian una actividad gubernamental ilegal que se equipara a la extorsión por parte de los inspectores que visitan los negocios o las calles.(75)

El Crimen Autorizado se extiende a muchas actividades (ver la tabla I donde incluimos ejemplos por categoría aunque se pueden encontrar más ejemplos en los medios) que incluyen: vender protección, policía corrupta, jueces y magistrados corruptos, políticos corruptos involucrados en actividades criminales, fuerzas del orden trabajando como criminales, tortura, legisladores trabajando para y con criminales, funcionarios públicos trabajando para criminales, abuso militar, funcionarios públicos protegiendo criminales, criminales designando funcionarios públicos, funcionarios públicos aprobando o estimulando violaciones legales.

Segunda conclusión. No todos los miembros del Estado están mezclados en actividades criminales, pero el Crimen Autorizado no necesita un número específico de personas o cierto porcentaje de involucramiento para ser una condición seria y preocupante. El impacto político que ha tenido en el mundo la desaparición de los 43 jóvenes en Iguala, muestra el gran peso de un suceso, aunque en este caso es un suceso mayor.(76) En el caso mexicano existen evidencias de lo profunda de esta asociación,(77) y que va desde gobiernos municipales con fuerte influencia de los carteles, falta de acción legal (78) ya sea por expedientes mal integrados de parte del Ministerio Público o por jueces liberando criminales y aunque no se le da la importancia adecuada, está el tema del traslado del dinero sucio a actividades legales, lo que se hace por medio de muchos mecanismos que parecen estar tolerados por el Estado.(79) Mientras más extendido está el Crimen Autorizado más dañado está el sistema y más complicada es la corrección.

Tercera conclusión. El Crimen Autorizado promueve una agenda criminal, pero en ciertas situaciones otro tipo de intereses pueden beneficiarse del mismo. En el Valle de Juárez un criminal protegido por las fuerzas del orden, o sea por el Estado, llevó a cabo asesinatos prolongados forzando al $90 \%$ de la población a abandonar sus casas y negocios, algunos de los desplazados culpan al gobierno, sosteniendo que desde que se informó sobre la existencia de gas en la zona hay inversionistas que se aprovechan de las propiedades vacías.(80)

Cuarta Conclusión. El Crimen Autorizado suplanta las principales funciones del Estado incluyendo, aunque no exclusivamente, la aplicación de la justicia, castigos y recompensas, mantienen ejércitos y cobran impuestos; penetra las instituciones de gobierno como las secretarías de seguridad pública o las direcciones de obras a nivel municipal, por lo tanto no existe un vacío en la estructura de poder y la sociedad se vuelve más vulnerable ante el 
sistema autoritario, que mantiene las condiciones de corrupción e impunidad que lo reproducen facilitando el avance del Crimen Autorizado.

La sociedad confronta una anomalía estructural porque con el Crimen Autorizado las instituciones siguen funcionando, persisten espacios de honestidad en el sistema y algunos criminales son castigados (muchas veces como parte de la guerra entre grupos criminales), con lo que se crea la impresión de que los criminales están controlados. Esta es la estrategia que ha seguido el gobierno mexicano con la detención del Chapo Guzmán: tratar de convencer a la sociedad -y al mundo-, que el problema de las drogas se ha resuelto con la detención de uno de los capos. Es posible pensar que estas "victorias" contra el crimen muestran que no todo el sistema está contaminado; por otro lado podemos pensar que el Crimen Autorizado le da una zanahoria al sistema (81) para que no pierda del todo la legitimidad y pueda seguir funcionando.

Si la simbiosis entre el crimen y el Estado se amplia y generaliza cubriendo mayores espacios institucionales (82) -por ejemplo el sistema de salud- estaremos ante otro tipo de sistema político, para el que todavía no hay definición.

Tabla I.

Ejemplos de formas del Crimen Autorizado en México

\begin{tabular}{|l|l|}
\hline $\begin{array}{l}\text { Agentes del orden } \\
\text { trabajando como } \\
\text { criminales }\end{array}$ & $\begin{array}{l}\text { Policías robando } \\
\text { http://www.eluniversaledomex.mx/toluca/negocios-cierran-por-asaltos- } \\
\text { senalan-a-policia-municipal.html } \\
\text { Jefe de policía clonaba patrullas para realizar trabajo ilegal } \\
\text { http://www.jornada.unam.mx/2014/10/04/politica/008n1pol }\end{array}$ \\
\hline Jueces corruptos & $\begin{array}{l}\text { Más de 600 jueces y magistrados castigados } \\
\text { http://contralinea.com.mx/archivo-revista/index.php/2012/02/05/ }\end{array}$ \\
$\begin{array}{l}\text { sancionados-mas-de-600-jueces-y-magistrados/ } \\
\text { http://www.eluniversal.com.mx/nacion/politica/la-inexplicable-riqueza- } \\
\text { del-ex-magistrado-que-libero-al-hijo-de-el-chapo }\end{array}$ \\
\hline $\begin{array}{l}\text { Políticos corruptos } \\
\text { involucrados en } \\
\text { actividades criminales }\end{array}$ & $\begin{array}{l}\text { Familiares de políticos involucrados en actividades criminales } \\
\text { http://www.indicepolitico.com/los-yunes-pinza-del-chantaje-en- } \\
\text { seguridad-y-justicia/ }\end{array}$ \\
\hline $\begin{array}{l}\text { Abuso militar } \\
\text { Doctor torturado por marinos } \\
\text { http://www.eluniversal.com.mx/nacion-mexico/2014/impreso/el- }\end{array}$ \\
\hline $\begin{array}{l}\text { Funcionarios trabajando } \\
\text { para criminales }\end{array}$ & $\begin{array}{l}\text { Alcalde cobraba cuotas para narcotraficante } \\
\text { http://www.elfinanciero.com.mx/politica/alcaldesa-de-huetamo-es- }\end{array}$ \\
\hline $\begin{array}{l}\text { detenida.html } \\
\text { http://www.eluniversal.com.mx/articulo/estados/2016/01/21/fueron- }\end{array}$ \\
$\begin{array}{l}\text { festejar-veracruz-y-los-desaparecen } \\
\text { Policía obliga a delinquir a policías } \\
\text { https://www.facebook.com/NO-a-la-corrupci\%C3\%B3n-de-los- }\end{array}$ \\
\hline $\begin{array}{l}\text { Folic\%C3\%ADas-del-Estado-de-M\%C3\%A9xico-143799748997273/ } \\
\text { o incentivando } \\
\text { actividades ilegales como } \\
\text { la venta de drogas y } \\
\text { bienes robados }\end{array}$ & \begin{tabular}{l} 
Priminales nombrando policías \\
\hline Criminales nombrando
\end{tabular} \\
\hline
\end{tabular}




\begin{tabular}{|l|l|}
\hline funcionarios públicos & $\begin{array}{l}\text { http://www.eluniversal.com.mx/nacion- } \\
\text { mexico/2015/impreso/crimen-ponia-policia-en-tierra-caliente- } \\
\text { 222442.html }\end{array}$ \\
\hline $\begin{array}{l}\text { Agentes del orden } \\
\text { protegiendo actividades } \\
\text { criminales }\end{array}$ & $\begin{array}{l}\text { Asaltaban con la complicidad de la policía } \\
\text { http://ciudadanosenred.com.mx/banda-asalta-en-el-metrobus-en- } \\
\text { complicidad-con-policias/ }\end{array}$ \\
\hline $\begin{array}{l}\text { Funcionarios trabajando } \\
\text { por o para los carteles }\end{array}$ & $\begin{array}{l}\text { Policías secuestrando personas } \\
\text { https://www.facebook.com/permalink.php?story fbid=76768736658424 } \\
\text { 1\&id=114643761888608 }\end{array}$ \\
\hline $\begin{array}{l}\text { Criminales actuando } \\
\text { como jueces o agentes } \\
\text { de fe pública }\end{array}$ & $\begin{array}{l}\text { Narcotraficante mediando en un caso de herencia } \\
\text { https://www.youtube.com/watch?v=ewJhCwYf4p4 }\end{array}$ \\
\hline $\begin{array}{l}\text { Criminales apoyando a, o } \\
\text { trabajando con } \\
\text { legisladores }\end{array}$ & $\begin{array}{l}\text { Diputada de Sinaloa con el chapo } \\
\text { http://www.excelsior.com.mx/nacional/2015/07/16/1035002 }\end{array}$ \\
\hline $\begin{array}{l}\text { Compra de votos para } \\
\text { blanquear dinero }\end{array}$ & $\begin{array}{l}\text { Buscaglia, Edgardo. 2015. Lavado de dinero y corrupción política. } \\
\text { México D.F.: Debate. }\end{array}$ \\
\hline
\end{tabular}

\section{Notas}

(1) Tokatlian, Juan Gabriel. Jacque a la guerra contra las drogas, Revista Anfibia, 2017. Recuperado de: http://www.revistaanfibia.com/ensayo/jaque-a-la-guerra-contra-las-drogas/ (2) Aunque más adelante profundizaremos en las distintas formas de asociación entre criminales y miembros del Estado, se puede tomar como ejemplo el caso de un magistrado de la Suprema Corte de Justicia de México, cuya fortuna se investiga al sospecharse cierto beneficio por parte de criminales. Para más información: http://www.eluniversal.com.mx/nacion/politica/la-inexplicable-riqueza-del-ex-magistrado-quelibero-al-hijo-de-el-chapo

(3) Buscaglia, Edgardo. Lavado de dinero y corrupción política, México D.F., Debate, 2015, p. 68.

(4) Schmidt, Samuel, Cervera, Luis, Botello, Adrián. "México: Territorialización de los homicidios. Las razones de la violencia en el norte del país", en Revista Realidad, Datos y Espacio. Revista Internacional de Estadística y Geografía, 8 (2).

(5) El ejemplo que tiene la sociedad sobre el beneficio de trabajar para o con criminales tiene un efecto pernicioso, hay quién piensa que los criminales son socialmente responsables, porque desarrollan obras sociales, económicas y hasta religiosas. Muchos se sorprenden cuándo al preguntarle a un niño qué quiere ser de grande este responde: sicario. Ese niño ha socializado experiencias y ve el beneficio de hacer "ese trabajo" cuyo riesgo se reduce al estar asociado al Estado.

(6) Usamos el concepto fuerzas del orden en el sentido de law enforcement.

(7) De la entrevista que El Chapo le dio a Sean Penn. "El Chapo Speaks. A secret visit with the most wanted man in the world", en Rolling Stone. Recuperado de:

http://www.rollingstone.com/culture/features/el-chapo-speaks-20160109\#ixzz3yUHz0DCh. Se infiere que él recibió información sobre un operativo en su rancho, por lo que lo abandonó tiempo antes del arribo de las fuerzas del orden.

(8) Ver http://intoleranciadiario.com/detalle noticia/131509/municipios/ordena-de-ductos-enpuebla-incontrolable; http://www.lajornadadeoriente.com.mx/2014/12/26/se-multiplica-24veces-la-ordena-de-ductos-de-petroleos-mexicanos-en-puebla/; http://www.milenio.com/estados/ordena_de_ductos_en_PueblaPuebla_ordenan_ductos_de_Pemex-Pemex_ductos_0_772722925.html (9) Criminales que imponen impuestos (pago por protección), imponen castigos (Sentencia a muerte) a los que no cumplen. Dos funciones (impuestos y castigos) exclusivas del Estado. 
(10) Un líder social, cuya identidad debemos mantener en secreto, que dedica buena parte de sus fuerzas y recursos a la lucha contra el secuestro, acudió a un alto mando de la policía federal pidiéndo ayuda para resolver un secuestro, y se dio cuenta que ese mismo comandante era el jefe de la banda de secuestradores. Un agente policíaco le confirmó a uno de los autores que en su primer fuga El Chapo estaba vestido de policía y fue escoltado por oficiales de alto rango.

(11) En el caso mexicano la Encuesta Nacional de victimización y percepción sobre seguridad (ENVIPE) considera los crímenes no reportados como "cifra negra" y sostiene que llega al 93.7\% de los crímenes cometidos. Ver: http://www.consulta.mx/index.php/estudios-einvestigaciones/otros-estudios/item/872-inegi-encuesta-nacional-de-victimizacion-ypercepcion-sobre-seguridad-publica-envipe-2016

(12) Preferimos usar gobernación que se refiere a la acción del gobierno como lo utiliza Dror, en lugar de gobernabilidad que es un concepto difuso con diversas definiciones. Dror, Yehezkel. The avant-garde politician. Leaders for a new epoch, Washington D.C., Westphalia Press, 2014 y Op. cit 1994.

(13) Arendt, Hannah. Sobre la violencia, España, Alianza Editorial, 2006 a , p. 66.

(14) Hermosa, Antonio. "La felicidad del mal (ensayo sobre Tucídides)". Res Publica, Vol. 19, no 1,2016 , pp. 35-47.

(15) Mixon, Don. Obedience and Civilization, London and Winchester, Pluto Press, 1989.

(16) "Of course the enemy had no weapons. They were powerless, weak men, women, and children. But the Reich couldn't be hoodwinked in such a manner. The Reich knew well that this enemy was worse, far more dangerous than foreign enemies in the field. That was why the Reich considered it most important to exterminate the enemy rather than to occupy whole countries with subjected populations" Weil, Jiří. Mendelssohn is on the roof, USA, Penguin, 1991, p. 45.

(17) Tal vez uno de los elementos del debate alrededor de Arendt Hannah. Lo que quiero es comprender, España, Trotta, 2006, es que Israel enjuició a Eichman mientras que debió haber enjuiciado al régimen Nazi, y a Eichman como uno de sus actores centrales, lo que no niega los horrores de lo que él hizo. Mixon, Op. cit. aclara que una persona que recibe una orden en contra de los valores morales puede y debe rehusarse a cumplirla, al no hacerlo, le será difícil probar inocencia por obedecer sin rehusarse a cumplir.

(18) Mixon, Op. cit., p. 43.

(19) "En todas las empresas ilegales, delictivas o políticas, el grupo por su propia seguridad, exigirá <<que cada individuo realice una acción irrevocable >> con la que rompa su unión con la sociedad respetable, antes de ser admitido en la comunidad de violencia. Pero una vez que un hombre sea admitido, caerá bajo el intoxicante hechizo de $<<$ la práctica de la violencia $>>$ Arendt, Op. cit., 2006무 p. 91.

(20) Hermosa, Op. cit.

(21) Es el caso de Rafael Aguilar.

(22) Gramsci, Antonio. Notas sobre Maquiavelo, sobre política y sobre el estado moderno, México D.F., Juan Pablos, 1975.

(23) No es el propósito de este artículo hacer un análisis profundo sobre el Estado y el gobierno, sino abordar esos elementos que nos llevan a ubicar de forma adecuada al crimen autorizado.

(24) Arendt, 2006a, Op. cit.

(25) Dror propone la categoría Razón de Humanidad que se enfoca en la calidad de vida de la sociedad en contra de la Razón de Estado. Dror Yehezkel. La Capacidad de Gobernar, México D.F., Fondo de Cultura Económica, 1994.

(26) Aquí podemos utilizar la definición de Marx de ideología en tanto que distorsión de la realidad, luego entonces el Estado controlado por los neoliberales engaña a la sociedad proponiendo medidas políticas en el discurso que no cumple en la realidad. Ver un resúmen sobre el neoliberalismo en México en Schmidt, Samuel y Rivera, Rubi. "La doctrina del shock en México", en Forbes México. Recuperado de: http://www.forbes.com.mx/la-doctrina-del- 
shock-en-mexico-los-neopols-en-el-poder-i/; http://www.forbes.com.mx/la-doctrina-del-shocken-mexico-los-cambios-estructurales-ii/;http://www.forbes.com.mx/la-doctrina-del-shock-enmexico-los-beneficiarios-y-iii/

(27) El concepto de Golpe de Estado, aunque es de uso común, es engañoso, porque involucra derrocar al gobierno, no destruir al Estado.

(28) Lipset, Seymour Martin. Political man: the social bases of politics, Baltimore, Johns Hopkins University Press, 1981.

(29) Sprinzak, Ehud. "Tahalijei de-legitimatzia bemishtar democrati", en Medina ve yahasim bein leumim, No. 6, Jerusalem, Universidad Hebrea de Jerusalem, Facultad de Ciencias Sociales, 1974; Sprinzak, Ehud. Democracy and illegitimacy: A study of the American and French Student Protest movements and some theoretical implications, Yale University. Ph. D. Disertation, 1971.

(30) Estados Unidos jugó un papel fundamental en el golpe de Pinochet contra Salvador Allende, y más adelante jugó un papel fundamental en el voto contra Pinochet que ayudó a reinstalar la democracia electoral. Estas externalidades son importantes y deben considerarse en el análisis.

(31) "A well regulated militia being necessary to the security of a free State, the right of the People to keep and bear arms shall not be infringed".

(32) "The US has an estimated 283 million guns in civilian hands. Each year about 4.5 million firearms, including approximately 2 million handguns, are sold in the United States. An estimated 2 million second hand firearms are sold each year.

The average number of guns per owner has increased from 4.1 in 1994 to 6.9 in 2004. More than 30,000 people are killed by firearms each year in this country. More than 30 people are shot and murdered each day. 1/2 of them are between the ages of 18 and 35". USA gun violence statistics. Recuperado de: http://heedinggodscall.org/content/pfctoolkit-10 (33) Hemos excluído el caso mexicano, porque en la guerra civil de 1910 no se destruyó el Estado, por larga que haya sido (11 años) la inestabilidad política.

(34) Op. cit. Arendt, 2006a , p. 70.

(35) Buscaglia Op. cit., p. 96.

(36) Galanter, Marc. La modernización de la ley. Material didáctico 81, Centro Interamericano de Desarrollo Rural y Reforma Agraria, Instituto Interamericano de Ciencias Agrícolas, OEA, 1969.

(37) Olvera, Ramón Gerónimo. Sólo las cruces quedaron. Literatura y narcotráfico, México, Instituto Chihuahuense de la Cultura, 2013, p. 163.

(38) Voltaire. Sf. Candido, Zadig, España, Novaro, p. 187.

(39) Weil Op. cit., p. 164.

(40) Becker, Ernest. La lucha contra el mal, México D. F., Fondo de Cultura Económica, 1977. (41) Noemi Klein en The shock doctrine, México, Paidós, 2014, sostiene que los neoliberales utilizan o crean el shock para aterrorizar y paralizar a la sociedad e introducir un paquete de políticas privatizadoras que concentran la riqueza y empobrecen a la sociedad. Muchas veces estos procesos se cruzan con el Crimen Autorizado como sugerimos en Schmidt y Rivera Op. cit. y en Schmidt, Cervera, Botello Op. cit.

(42) Arendt 2006, Op. cit., p.104.

(43) Agradecemos a Baltasar Garzón por esta aclaración.

(44) El juramento del presidente de Estados Unidos dice: "I do solemnly swear (or affirm) that I will faithfully execute the Office of President of the United States, and will to the best of my ability, preserve, protect and defend the Constitution of the United States." Lo mismo juran los militares.

(45) Op. cit., 2006, p. 107.

(46) Galtung, Johan. "Violence, peace and peace research". Journal of peace research, 6 (3), pp. 167-191.

(47) Engels, Federico. "Carta a Konrad Schmidt” en Marx-Engels. Obras Escogidas, Moscú, Editorial Progreso, 1969. 
(48) Mixon, Op. cit., p. XII.

(49) "Authorized crimes are means of carrying out policies of the military and of the state. The words 'authorized crimes' contain a paradox, for authorization makes a particular destructive or vicious act no longer a crime" en Mixon 1989, Op. cit., p. 5.

(50) Esta es una de las explicaciones sobre los 43 estudiantes desaparecidos en Iguala (el caso es conocido como Ayotzinapa), y lo mismo se repitió en Veracruz en enero de 2016. En ambos casos, los jóvenes fueron subidos a patrullas y entregados al cartel, y desde entonces no se conoce su paradero.

(51) Una excusa común es que el gobierno estadounidense no sabe si representan un riesgo para la sociedad. Las víctimas son victimizadas institucionalmente.

(52) La policía, o fuerzas del orden, ya sea municipal, estadual o federal son el Estado.

(53) Bakunin, Michael. "La libertad" en Portal Archivo Miguel Bakunin. Recuperado de: https://miguelbakunin.wordpress.com/2008/02/12/la-libertad/

(54) Galtung Op. cit., p. 171.

(55) La información puede encontrarse en el portal:

https://en.wikipedia.org/wiki/Structural violence

(56) Las acciones encubiertas de un país en otro son criminales en el país donde se efectúan pero no lo son para el país que ordena la acción. Hay diversos conflictos diplomáticos cuándo éstas acciones son descubiertas, o bien los agentes detenidos.

(57) El consenso se ha asumido como un elemento generalizado, sin embargo, las acciones represivas en contra de un segmento social implican que no necesariamente todos otorguen su aprobación o aceptación. Habrá que diferenciar entre el consenso derivado de una elección, del consenso alrededor de diferentes decisiones políticas.

(58) La cultura legal implica respetar las leyes por libre volición o ¿por miedo a las consecuencias en el caso de ser violadas?

(59) Los interesados pueden leer la versión social de la misma en Wikipedia, https://en.wikipedia.org/wiki/Patriot Act, y la del gobierno en la explicación del Departamento de Justicia disponible en http://www.justice.gov/archive/ll/highlights.htm.

(60) Galtung, Op. cit., p. 184.

(61) Es posible que una insurrección pueda derrotar y derrocar al gobierno sin destruir al Estado.

(62) Bourdieu, Pierre and Loïc Warquant. SF. "Symbolic violence", in An Invitation to Reflective Sociology (pp. 167-173), Chicago University Press, Chicago, 1992.

(63) Información extraída de: http://www.elblogdelnarco.com/2016/01/diputada-amiga-de-elchapo-guzmán-buscaba-detener-lucha-antinarco-en-sinaloa-.html

(64) La definición fue obtenida del portal de Wikipedia:

https://en.wikipedia.org/wiki/Structural violence. Por su parte, Hermosa agrega: "un contexto permanente de incertidumbre en el que el miedo recoge una cosecha de odio que sólo se agota dando muerte a los rivales". Y con esto "el conjunto de palabras en las que los sujetos ordenaban el mundo cae por completo", honor y respeto se convierten en excusa para exterminar. Hermosa, Op. cit., 2016.

(65) Aquí debe considerarse la predisposición a la corrupción de los mexicanos y la incorporación en la cultura popular de expectativas sociales de beneficio extra legal en el acceso al poder. Esto puede ejemplificarse con dichos como "no me den ponganme dónde hay", "el que no tranza no avanza" o el que la gente se sorprenda de que un político sea "pendejo" para ser atrapado. El reclamo parece ser que se "democraticen" las oportunidades para corromperse.

(66) Muchas fortunas tienen orígenes oscuros. En una ciudad fronteriza era famoso un empresario que controlaba la cerveza y según vox populi controlaba la prostitución, simultáneamente sostenía un hospital para mujeres, era filántropo de la educación y aportaba recursos para campañas políticas.

(67) Hay un error en el análisis que sin embargo no lo descalifica. Esta basado en los medios, que en el caso mexicano se han corrompido ante el Estado desde el siglo XIX Picato, Pablo. 
The tyranny of opinion. Honor in the construction of the Mexican Public sphere, Duke University Press, 2010. Y en las últimas décadas sucumben ante el poder de los criminales. Los medios distorsionan la verdad, aunque no lo hacen siempre. No sabemos en que casos la información es correcta y en cuáles ha sido distorsionada, ni que tanto ha sido distorsionada; asumimos que en ciertos casos es válida y correcta, especialmente durante catástrofes y tragedias sociales, como es el caso del Crimen Autorizado. Durante el gobierno de Felipe Calderón (2006-2012) varios periódicos, especialmente Reforma, llevó una cuenta diaria de asesinatos, el gobierno de Peña Nieto (2012) forzó el silencio de los medios para mostrar que su estrategia funcionaba.

(68) Transparencia internacional define corrupción como "Corruption is the abuse of entrusted power for private gain. It can be classified as grand, petty and political, depending on the amounts of money lost and the sector where it occurs. Corruption corrodes the fabric of society. It undermines people's trust in political and economic systems, institutions and leaders. It can cost people their freedom, health, money - and sometimes their lives". Información disponible en: http://www.transparency.org/what-is-corruption/. Discrepo sobre el impacto sobre el tejido social e insisto en que el impacto principal de la corrupción es sobre el tejido político.

Wikipedia define corrupción como: "Corruption is a form of dishonest or unethical conduct by a person entrusted with a position of authority, often to acquire personal benefit. Corruption may include many activities including bribery and embezzlement, though it may also involve practices that are legal in many countries. Government, or 'political', corruption occurs when an office-holder or other governmental employee acts in an official capacity for personal gain.

https://en.wikipedia.org/wiki/Corruption

(69) Para más información ver: http://internacional.elpais.com/internacional/2015/05/09/actualidad/1431193197_679747.html

(70) En México se escucha con sorpresa que alguien haya sido torpe al corromperse y ser atrapado, no al hecho de la corrupción per se. Hay quién considera que los narcos son empresarios socialmente responsables, al generar empleos y pagar bien; así mismo construyen diversas obras, incluidas las iglesias, con lo que logran simpatía social. (71) El número uno es el menos corrupto. Al respecto puede consultarse: https://www.transparency.org/cpi2014/results\#myAnchor1

(72) Schmidt, Samuel. El estado suplantado. Mexico and the world. PROFMEX journal, Vol. XVII, No. 5. (early fall), 2012. Recuperado de: http://profmex.org/mexicoandtheworld/volume17/5earlyfall2012/Estado_suplantado_Schmidt.p df

(73) Entre los muchos casos en que la iglesia católica mostró una actitud positiva hacia los criminales se pueden ver los siguientes casos donde se expresa el perdón criminal (ver: http://www.prensalibre.com/internacional/lglesia-pide-perdonar-narcos-

asesinos 0 856114431.html), la complicidad entre la curia y narcotraficantes (ver: http://www.bbc.com/mundo/noticias/2012/03/120322 mexico iglesia narco visita papa aw.s $\underline{\mathrm{html}}$ ); las capillas de los "narcos santos" (ver:

http://www.elmundo.es/internacional/2015/07/22/55afdc9f22601db8438b459c.html); y como no es solamente un problema mexicano, también puede rastrearse casos en Estados Unidos (ver: https://www.youtube.com/watch?v=C3yMu0 oF1g), Colombia (ver: http://eldia.com.do/iglesia-de-rd-era-usada-para-lavado-por-narcos/)

(74) Schmidt, Op. cit, 2012.

(75) Un funcionario del área de salud de la Ciudad de México nos comentó que los inspectores de salud se presentaban a cobrar el sueldo una vez cada varios meses, sus ingresos estaban conformados por la extorsión.

(76) Hay sucesos con impacto local, como el levantamiento zapatista en 1994, o los estudiantes de Iguala que trascienden las fronteras nacionales mostrando la verdadera cara del autoritarismo mexicano. Convendría analizar porque otros sucesos, como tragedias mineras se logran enterrar por el gobierno minimizando su impacto. 
(77) Schmidt, Samuel y Spector, Carlos. 'Authorized Crime' in Mexico A Paradigm to Explain Violence. Mexico and the World. PROFMEX Journal, 18, (6), 2013 (Fall). Recuperado de: http://www.profmex.org/mexicoandtheworld/volume18/6fall2013/Authorized_Cri me_in_Mexico.pdf "Viridiana Rios and Michele Coscia (2012) have documented that organized crime has played a supporting role in the election of several congressman, and they note that the present speaker of the house (PRI) has been accused of having ties with drug traffickers [in 2015 he became president of his political party]. They also suggest that in 2012 drug traffickers were political actors in 731 municipalities-- $30 \%$ of the municipalities in Mexico.

Grayson, however, suggests that the number of criminals involved in it is as high as all of Mexico's municipios, which number 2,435 producing what we consider zones of impunity in 233 zones (Lacey quoted by Grayson). In the war on drugs Mexico fights drug cartels and itself. The complex complicity between criminals and authorities produces a paradox were the legitimate violence is used against society". Grayson, George. Mexico narco violence and a failed state, New Brunswick, Transaction books, 2011. Rios, Viridiana and Michele Coscia. Using Google to track Mexican drug trafficking organizations. Harvard CID Research Fellow \& Graduate Student Working Paper 57, August, 2012.

(78) Schmidt y Spector, Op. cit. 2013, " $80 \%$ of the 623,213 people detained in operations against organized crime and drug trafficking in Mexico during the Felipe Calderon administration (2006-2012) are free provisionally or definitively".

Hannah Arendt, Op. cit., 2006a describe un problema de falta de eficiencia policíaca, aunque ella no lo enmarca en este fenómeno.

(79) Buscaglia, Op. cit., 2015, aborda el tema del traslado de dinero del narco hacia países desarrollados dónde es posible invertirlo en actividades legítimas, lo que podría explicar el crecimiento de Estados Unidos y países europeos aún en épocas recesivas. Schmidt, Samuel y Spector, Carlos. Tras el muro, México D.F., Cámara de Diputados, 2013a sugieren la posibilidad de que dinero sucio entre como remesas internacionales a México, lo que ayuda a equilibrar la macroeconomía. A la misma conclusión llega García Zamora. Migración, remesas y desarrollo local, Zacatecas, Universidad de Zacatecas, 2003.

(80) Ver información en: http://www.breitbart.com/texas/2015/10/27/mexican-energyboomtown-residents-flee-blame-government-violence/\#disqus_thread 1/6;

http://diario.rWmicrositios/Ptmte-internacional-Guadalupe-Tornillo/

Ver también Schmidt, Cervera y Botello 2017.

(81) Nos comentó un abogado penal en El Paso, Texas, que hay criminales que negocian con las agencias anti drogas y consecuentemente con los jueces, para entregar camellos a cambio de reducción en las sentencias. Esto es Crimen Autorizado.

(82) Según la Comisión Nacional de los Derechos Humanos el 70\% de las cárceles de México están controladas por los criminales. Ver Gonzalez de Alba, Luis. "El autogobierno en las cárceles", Nexos, April, 2016, pp. 78-79.

Imison, Paul. "Can Mexico's lawless prisons be reformed?" Eldailypost, April 27, 2016. Recuperado de: http://www.eldailypost.com/security/2016/04/can-mexicos-lawless-abusivedysfunctional-prisons-be-reformed/

Recibido: marzo de 2017.

Aprobado: agosto de 2017.

\section{Para citar este trabajo}

Schmidt, S.; Spector, C. "Crimen autorizado. Una Revisión” en Cuadernos de H Ideas [En línea], vol. 11, no 11, diciembre 2017, consultado...; URL: http://perio.unlp.edu.ar/ojs/index.php/cps/article/view/4541 
Cuadernos de H Ideas, vol. 11, no 11, diciembre 2017. ISSN 2313-9048 